\title{
Recommendations for the Aluminum and Iron-Containing Composite Flocculants-Coagulants Use for the Purification of Natural River Waters and Industrial Wastewater
}

\author{
Kudryavtsev $\mathrm{P}^{1 *}$ Kudryavtsev $\mathrm{N}^{2}$ \\ ${ }^{1}$ Professor, Deputy Director for Research and Development, KUD Industries PN Ltd - Israel Technology Research Center, Israel \\ ${ }^{2}$ Director, KUD Industries PN Ltd - Israel Technology Research Center, Israel
}

\begin{abstract}
Coagulation is the most widespread method of natural and wastewater purification from the bulk of colloidal, finely dispersed, and partially dissolved contaminants. The characteristics of the new composite flocculants-coagulants ASFC and ISFC developed by the authors compared to traditional aluminum and iron salts are given. The characteristics of natural waters, which were used to study the efficiency of using the obtained flocculants-coagulants, are given. To compare the effect of the developed materials with known products, we used such a parameter as their coagulation ability to purify high-color water from the Orsha river and medium-color water from the Volga and Tvertsa rivers in Russia. An attempt is made to assess the effect of magnetic treatment of the developed composite flocculants-coagulants. Based on the conducted research and production tests, recommendations were developed to use aluminum and iron-containing composite flocculants-coagulants to purify natural river waters and industrial wastewaters.
\end{abstract}

Keywords: Coagulation, Flocculation, Composite flocculants-coagulants, ASFC, ISFC, Water purification

\section{Introduction}

One of the most important elements of a modern water supply system is a water treatment complex. There is currently an intensive expansion of the use of various water sources, including those not used before. Anthropogenic and technogenic almost uncontrolled water bodies' pollution continues, and the requirements for the quality of the water used are increasing. Many industrial enterprises do not have treatment facilities and discharge wastewater into natural reservoirs without treatment. For example, according to rough estimates, about 5 million $\mathrm{m}^{3}$ of domestic wastewater is discharged into Russia's water bodies without treatment and 4 . 2 million $\mathrm{m}^{3}$ - with insufficient treatment. Water in natural water sources is often polluted with highly toxic substances. As a result, today, in several countries and regions, many natural water bodies have become heavily polluted, which has led to the impossibility of their further use for various purposes, and primarily for household and drinking water supply. ${ }^{1-5}$

Natural water purification, improvement of existing and development of new methods, and water treatment technologies are of paramount importance. One of the most widely used water treatment methods in systems using water from open sources is coagulation water treatment. Coagulation is a process of coarsening of dispersed particles due to their interaction and integration into ag-

\begin{tabular}{|l|l|}
\hline Quick Response Code: & *Corresponding author: Kudryavtsev P, Professor, Deputy Director for Research and Devel- \\
opment, KUD Industries PN Ltd - Israel Technology Research Center, Israel \\
Received: 23 November, 2020 \\
Citation: Kudryavtsev P, Kudryavtsev N. Recommendations for the Aluminum and Iron-Con- \\
taining Composite Flocculants-Coagulants Use for the Purification of Natural River Waters and \\
Industrial Wastewater. Glob Scient Res Env Sci. 2020;1(1):1-10. D0I: \\
$10.53902 /$ GSRES.2020.01.000503
\end{tabular}


gregates. The use of the coagulation method for treating polluted waters is expanding every year.

When carrying out the coagulation process, the solution is the main technological task of water purification from colloidal-dispersed pollution. It is possible to improve the quality of purified water using the coagulation method by removing some of its impurities. The most widespread in the world is industrial wastewater treatment using mineral coagulants (aluminum and iron salts) and flocculants. The main purpose of coagulants and flocculants is to increase particles' size due to their aggregation and increase water purification efficiency by filtration, settling, or flotation methods. Water purification with coagulants and flocculants is used to remove surfactants, colloidal and finely dispersed contaminants. These include hydrophobic substances such as petroleum products, oils, and fats; hydrophilic substances such as humic compounds, polysaccharides, proteins, and lignin; organic compounds and mineral impurities include clay particles, oxides, and carbonates of various metals. Simultaneously, removing dissolved organic and mineral contaminants from the water can occur, which can be adsorbed by hydrolysis products of coagulants or enter chemical interaction with coagulants flocculants with the formation of poorly soluble compounds. Such substances are salts of humic and fulvic acids, anionic and cationic surfactants, dyes, phosphates, complex compounds of heavy metals, etc.

Among the reagents used in coagulation wastewater treatment, the most common are inorganic coagulants. Inorganic coagulants are associated with availability, a large resource base, low cost, and high efficiency. In recent years, new types of inorganic coagulants with improved technical characteristics have begun to be produced, contributing to the expansion of the coagulation method's applicability and an increase in its efficiency. Also, the range of organic and inorganic flocculants is expanding. Various flocculants can be used both independently and in conjunction with coagulants, expanding this method's capabilities and making it an irreplaceable part of technological water purification processes. Earlier, we have developed composite flocculants-coagulants based on soluble compounds of aluminum and silicon, as well as iron and silicon. ${ }^{6}$ The matrix isolation technology was developed to combine incompatible aluminum, iron, and silicon compounds, making it possible to obtain them in the solid form. ${ }^{7,8}$ This form of developed materials allows them to be stored for a long time, safely transported, and quickly used in places of use.

This work is a continuation of a series of our articles devoted to wastewater treatment with composite coagulants-flocculants obtained based on the technology we have developed for their production in water convenient for their storage, transportation, and use at various natural and wastewater treatment facilities. ${ }^{9-17}$ This work analyzes the characteristics of wastewater pollution removed using a new group of reagents - composite coagulants-flocculants. The efficiency of their application for the purification of waste and natural waters is considered. The ways of choosing the most effective reagent and improving coagulation-flocculation wastewater treatment are substantiated and presented. Recommendations have been developed to use aluminum and iron-containing composite flocculants-coagulants to purify natural river waters and industrial wastewaters.

This article presents recommendations on using produced aluminum and iron-containing coagulants to purify the natural river and industrial wastewater. The recommendations were developed based on studies of their coagulating ability, presented in previously published works. ${ }^{10,13,16,17}$ The presented article substantiates the recommendations for coagulants aluminum-silicon flocculant-coagulant ASFC and iron-silicon flocculant-coagulant ISFC. Their additional studies are demonstrated.

\section{Justification of the Chosen Research Direction}

One of the ways to increase the efficiency of natural and wastewater treatment is to use new, highly effective reagents that would meet the following requirements:

- High coagulation and flocculation activity.

- $\quad$ Convenience and ease of use.

- Low cost

The tested coagulants ASFC and ISFC, which are powdered reagents, readily soluble in water, whose diluted solutions are stable during storage, fully satisfy these requirements in terms of their commercial characteristics and chemical composition. The coagulants ASFC and ISFC, in contrast to the sulfate salts of aluminum and iron, contain silicon compounds and should exhibit coagulant and flocculant properties. In this regard, in this work, studies were carried out on the effectiveness of using these reagents for the purification of natural waters and oily wastewater, for which the coagulation method is widely used, based on which recommendations for the use of coagulants ASFC and ISFC were developed.

In the second half of the last century, both in Russia and abroad, many works devoted to using magnetic fields to intensify various technological processes associated with water systems appeared. The method is attractive for its technological simplicity and low implementation costs. The general case's magnetic treatment method consists of passing water or aqueous systems (pulp, reagent solutions, suspensions) through magnetic fields..$^{20}$ In several cases, magnetic treatment of reagent solutions and anhydrous reagents turns out to be useful. For example, treating a sodium oleate solution increases the adsorption of this reagent on phosphorite, fluorite, dolomite, and quartz. Also, the treatment of an aqueous water glass solution enhances this reagent's suppressive ability. ${ }^{18-20}$

According to ${ }^{20}$ during coagulation of suspensions, their sedimentation rate increases, while the sediment's water permeability on the filters also increases. By reducing the clogging of the filter cloth's pores, the filtration rate increases, and the cloth's life is increased. Also, in works, ${ }^{20}$ it was found that after magnetic treatment of water, the sedimentation rate of the fine suspended matter contained in it increases by $20-90 \%$. This positive effect is also manifested in adding coagulants such as ferrous sulfate, aluminum sulfate, etc., to the water that has undergone magnetic treatment. In 
this case, there is a decrease in the electrokinetic potential of colloidal solutions of aluminum hydroxides, etc. ${ }^{20,21}$ However, the effect is insignificant at very water high-turbidity (above $500 \mathrm{mg} / \mathrm{L}$ ). ${ }^{22}$ It should be emphasized that the physical nature of the processes occurring during the magnetic treatment of water and water systems has not yet been clarified. The existing hypotheses on this issue are reduced to the idea of a change in water structure under a magnetic field's influence. There is much very contradictory information about changes in water's magnetic field, such as viscosity, density, electrical conductivity, surface tension, and some others. For systems of water purification by reagent methods, the following observations are of particular interest: the efficiency of magnetic treatment of water increases with an increase in the concentration of various ions in it; as a result of magnetic treatment, the surface tension of solutions of several chemical compounds changes greatly; the wett ability of minerals with water also changes after exposure to a magnetic field; under certain modes of magnetic treatment, the chemical activity of oxygen dissolved in water increases significantly. ${ }^{20}$ In this work, an attempt was made to assess our composite flocculants-coagulants' effect of magnetic treatment. The reagents were processed in magnetic fields created using electromagnets with a magnetic field strength of up to 2000-3000 Oe. In this regard, in this work, studies were carried out on the effect of such a magnetic treatment of the developed reagents for the purification of natural waters and oily wastewater, for which the coagulation method is widely used, based on which recommendations for the use of coagulants ASFC and ISFC were developed.

\section{Techniques and Objects of Research}

\section{Research objects}

The work used the well-known standard methods of research and analysis set out in previous reports. Coagulants' effectiveness was assessed by reducing water pollution and the optimal dose value at which the greatest reduction in turbidity, color, and oil content is achieved. Simultaneously, the $\mathrm{pH}$ value of the purified water was monitored. Using ferrous sulfate and the ISFC coagulant, the water $\mathrm{pH}$ adjustment to optimal values ( $\mathrm{pH} 9.2 \div 9.8$ ) was carried out using a $0.4 \% \mathrm{NaOH}$ solution. Coagulants were dosed into purified water in the form of $1 \%$ aqueous solutions (based on aluminum or iron oxide). The coagulants' effectiveness was determined by the trial coagulation method on a laboratory installation "Drop" with mechanical stirring according to the scheme: mixing, flocculation, and settling. Mixing was carried out for one minute at an average rate gradient $\mathrm{G}=500 s^{-1}$, flocculation for 5 minutes at $\mathrm{G}=50 \mathrm{~s}^{-1}$. The settling was carried out for $5 \mathrm{~min}$ to isolate impurities with a hydraulic particle size of more than $0.03 \mathrm{~mm} / \mathrm{s}$. The experiments were carried out on real natural or wastewater described in. ${ }^{10}$ Natural water had turbidity range from 10 to $25.6 \mathrm{mg} / \mathrm{L}$, color from 85 to 2880 on the chrome-cobalt scale, with a pH from 7.48 to 7.78 . Waste oily water had turbidity from 47 to $154 \mathrm{mg} / \mathrm{L}$, the content of oil products from 5.5 to $140 \mathrm{mg} / \mathrm{L}$, with a $\mathrm{pH}$ in the range from 6.9 to 7.6 .

The characteristics of the studied coagulants are presented in. ${ }^{16}$ The effectiveness of the coagulants ASFC and ISFC was compared with the effectiveness of ferrous sulfate and aluminum sulfate. Doses of coagulants were measured in $\mathrm{mg} / \mathrm{L}$ for aluminum or iron oxide. This article also presents additional experiments comparing the efficiency of using for purification of natural waters activated at different frequencies of a pulsed magnetic field and the original samples of ASFC and ISFC. The products were activated in a magnetic field according to the method described in. ${ }^{20}$

\section{Trial coagulation technique}

The trial coagulation method makes it possible to select a coagulant or flocculant to determine its optimal dose and effectiveness for purifying the water under study. The trial coagulation method's essence is water treatment with reagents in cylinders or glasses under a certain standard mode of mixing and flocculation or under conditions that simulate coagulation treatment at existing treatment facilities. At existing wastewater treatment plants for trial coagulation, any method adopted at the plant can be used. It gives a sufficiently good agreement between the doses determined in the laboratory and required for the facilities' normal operation. If these doses differ significantly from each other, then the appropriate adjustments should be made to change the intensity, time, and mixing method. Mixing is usually done with a mechanical stirrer, first quickly distributing the reagent evenly in the water. Slowly to create large, rapidly settling flocs of contaminants that are coagulated. For this purpose, special installations "Drop" and "Jar-test" are used, allowing to process simultaneously up to 6 samples of wastewater and to carry out mixing with mechanical stirrers with an adjustable speed in the range from 10 to 200rpm (Figures 1 and 2). Stirring on a magnetic stirrer or manually (with a glass rod, turning the cylinder) is allowed.

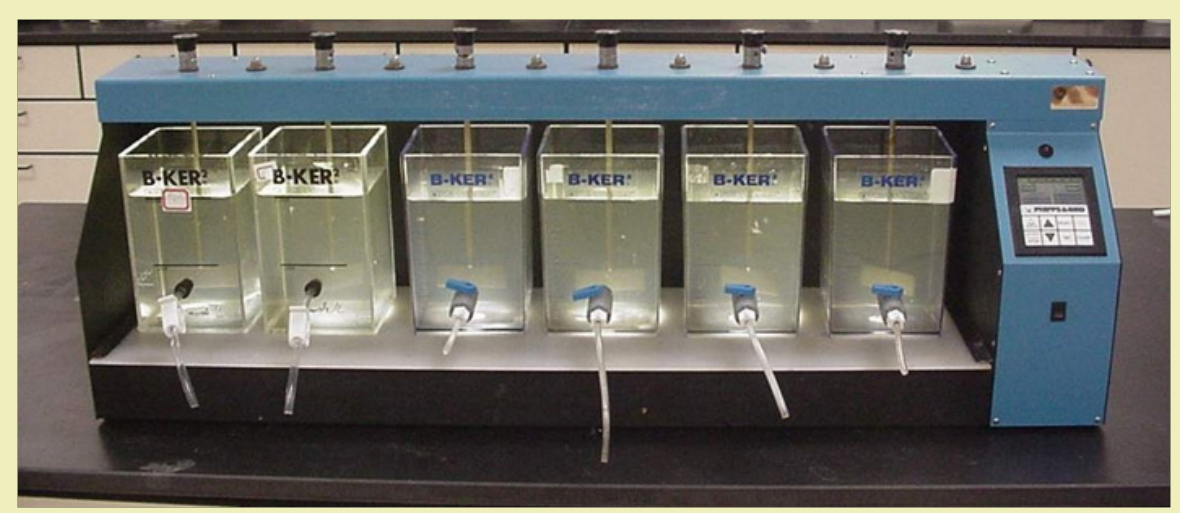

Figure 1: Installation of trial coagulation "Drop." 


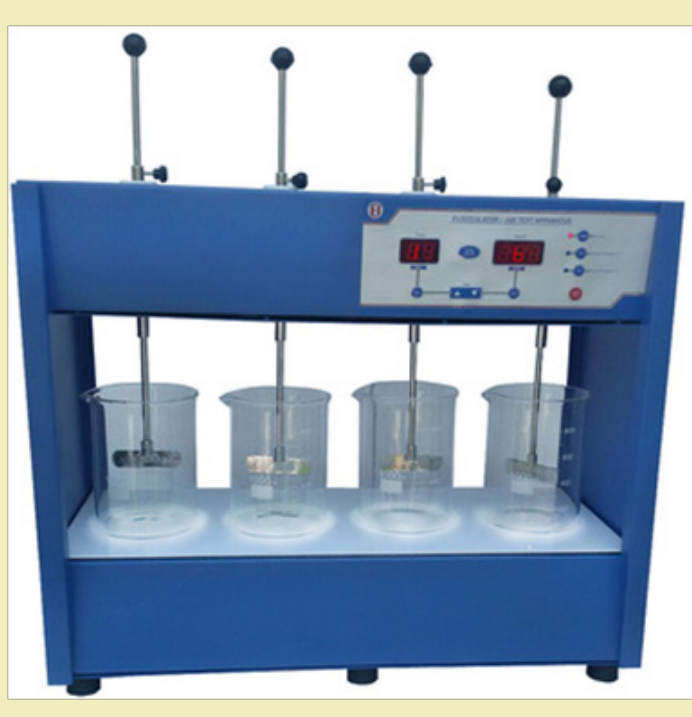

Figure 2: Jar Test setup for coagulation tests.

The criterion for the effectiveness of the reagent and the choice of the optimal dose is the minimum settling time (floating up) of the formed flakes, the quality of the settled wastewater (transparency, turbidity, the content of oil products, suspended solids, and other contaminants), the volume and characteristics of the resulting sediment. Simultaneously, during the entire settling time (up to 30 minutes), visual observations of the clarification process are carried out. The time of the appearance of small, large flakes and complete clarification is noted.

When conducting experiments on the coagulation of water, different coagulant doses are added to glasses with untreated water in the form of $1-5 \%$ solutions. Flocculants are added in the form of $0.1-0.05 \%$ aqueous solutions. Doses of reagents vary in the range covering the assumed optimal dose. For heavily contaminated water, the dose range expands in the direction of increasing. Doses of reagents are taken according to the active part or according to the commercial product. It is more expedient to compare the effectiveness of various reagents based on their active substance content. The recalculation of doses of reagents for commercial products and volumes of dosed solutions of coagulants and flocculants is carried out according to the formulas:

$$
\mathrm{D}_{\text {cr }}=\left(\mathrm{D}_{\text {act }} \cdot 100\right) / \mathrm{C}_{\mathrm{r}}
$$

Where $D_{c \mathrm{r}}$ - the dose of the commercial reagent, $\mathrm{kg} / \mathrm{m}^{3}$ of wastewater; $D_{\text {act }}$ - the dose of the reagent for the active substance, $\mathrm{kg} /$ $\mathrm{m}^{3}$ of wastewater; $C_{r}$ - the concentration of a commercial product by active substance, wt. \%. For reagents in liquid form, the dose of a commercial product in volume units can be found by the formula:

$$
\mathrm{V}_{\mathrm{cr}}=\left(\mathrm{D}_{\mathrm{act}} \cdot 100\right) /\left(\rho \cdot \mathrm{C}_{\mathrm{r}}\right)
$$

Where $V_{c r}$ - the dose of commercial liquid reagent, $\mathrm{m}^{3} / \mathrm{m}^{3}$ of waste water; $\rho$ - the marketable product's density, $\mathrm{kg} / \mathrm{m}^{3}$.

The density of dosed 1-5\% aqueous coagulants' solutions is determined by a hydrometer or taken from reference books. The den- sity of diluted 0.1 and $0.05 \%$ aqueous flocculants' solutions differs little from water density and can be taken equal to 1 .

\section{Determination of the optimal dose of coagulant and floc- culant for independent use}

Different doses of coagulant or flocculant are added to 6 beakers with crude water (volume $0.5 ; 1.0 ; 1.5$ or 2.01 ), mix rapidly at $150 \mathrm{rpm}$ for $1 \mathrm{~min}$, and then slowly at $50 \mathrm{rpm}$ for $5-10 \mathrm{~min}$. Such conditions make it possible to obtain large flakes. Small flocs can be formed if the given coagulant is ineffective or the $\mathrm{pH}$ value is not optimal in using inorganic coagulants, or the mixing time is insufficient. In the latter case, slow water addition to mixing the sample treated with a coagulant, for 5-10minutes. For adjusting $\mathrm{pH}$ to be simultaneously or after the addition of coagulant in the wastewater to enter the alkaline reagent solution in a $1-5 \%$ solution. The consumption of an alkaline reagent $\left(D_{\text {alk }}\right)$, depending on its type to compensate for the acidity introduced by the coagulant, is determined by the formula:

$$
\mathrm{D}_{\mathrm{alk}}=\mathrm{K} \mathrm{D}_{\mathrm{c}} / \mathrm{M}
$$

Where $\mathrm{D}_{\mathrm{c}}$ - coagulant dose, $\mathrm{mg} / \mathrm{L} ; \mathrm{M}$ - equivalent (molecular) mass of the coagulant, $\mathrm{mg} / \mathrm{mg}$ - $\mathrm{mol}$; $K$ - equivalent mass of alkaline reagent, $\mathrm{mg} / \mathrm{meq}$.

After the end of mixing, the resulting flocs are left to settle. The settling time is selected based on the flocs' settling rate in the range from 1 to $30 \mathrm{~min}$. The purified water quality is assessed visually or quantitatively according to the required indicator (color, turbidity, oil content, etc.). For this, the volume of wastewater required for analysis is taken by a siphon from each beaker. The results obtained are entered into tables. For clarity, the dependencies of the main indicators of the quality of treated wastewater on the coagulant dose or flocculant can be expressed graphically. The coagulant's optimal dose corresponds to the dose at which the maximum or required water clarification effect is achieved with the shortest or specified lag time.

\section{Determination of the optimal dose of a flocculant when used together with a coagulant}

In six beakers with untreated water (volume $0.5 ; 1.0 ; 1.5$ or $2.0 l$ ) add the same dose of coagulant (optimal or less than optimal by $25-50 \%$ ), found as shown in part 2.1 , the contents of the glasses are quickly stirred at $150 \mathrm{rpm}$, then different doses of the flocculant are added in the studied dose range, additionally stirred intensively at $150 \mathrm{rpm}$, then slowly at $50 \mathrm{rpm}$ for $5-10 \mathrm{~min}$ further settling, sampling and analysis of samples is carried out in the same way as in clause 2.1 .

\section{Experimental Part}

\section{The effectiveness of the use of coagulants ASFC and ISFC for the purification of natural waters}

Coagulation studies were carried out on the Orsha, Volga, and Tvertsa rivers' river waters and had low turbidity. The samples have different colors and were taken in Tver. The studies were carried out using coagulants ASFC and ISFC and basic coagulants, 
aluminum sulfate (AS) and iron (II) sulfate, ${ }^{16}$ with the following general results obtained. The main indicator that determines the dose of coagulants is the initial color of natural water. The optimal dose of coagulants ASFC and AS increases with an increase in the original watercolor (Figure 3). The type of coagulant affects the optimal dose at the high color of the source water. To purify the Orsha River's water, which has a high color, the coagulant ASFC is required in a lower dose than AS. For the Tvertsa and Volga rivers' waters with an average color, the doses of the reagents ASFC and AS are the same.

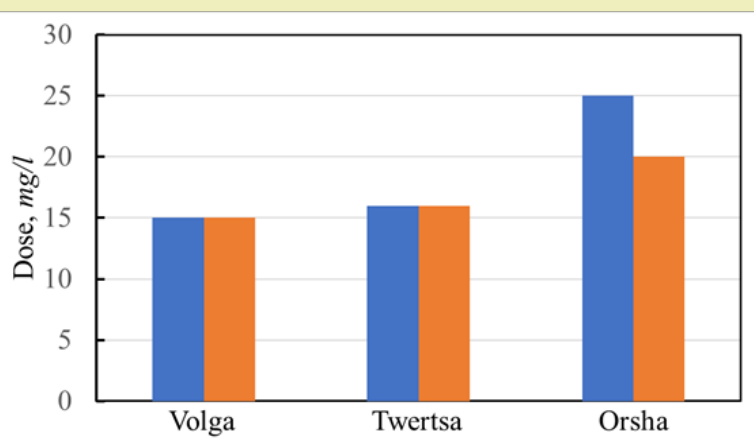

Figure 3: Dependence of the optimal dose of coagulant on the initial color of river water.

The effectiveness of reducing the source water's color and turbidity largely depends on the type of coagulant. Studies have shown that iron-containing coagulants ISFC and iron sulfate (IS), in contrast to aluminum-containing coagulants, are unsuitable for purifying colored natural waters Fe2+ ions form colored soluble complexes with humic and fulvic acids. As a result, the initial water's color with an increase in the dose of coagulant first increases and then begins to decrease but remains significantly higher than the required standards (Figure 4).

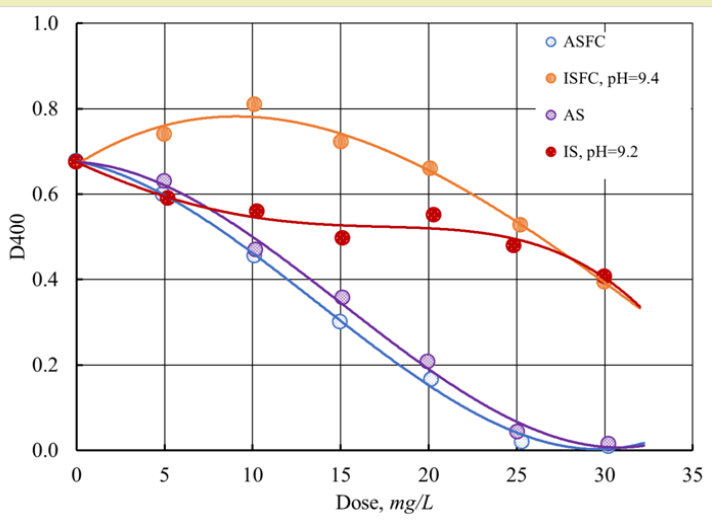

Figure 4: Dependence of chromaticity (D 400) coagulated and settled the water of the Orsha river.

The greatest reduction in turbidity and color is achieved when water is treated with optimal doses of aluminum-containing coagulants ASFC and aluminum sulfate (Figure 5). Moreover, the additional introduction of the cationic flocculant Praestol 650 reduces the treated water's turbidity to a greater extent when used together with ASFC than with aluminum sulfate.

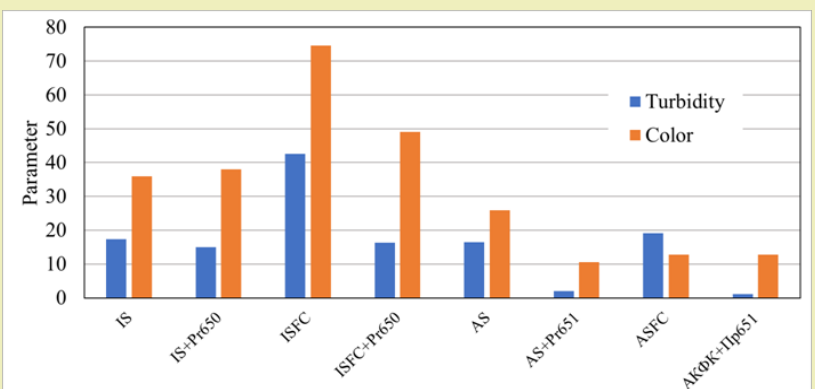

Figure 5: The effectiveness of reducing the color and turbidity of the Volga water coagulants $(15 \mathrm{mg} / \mathrm{L})$ and together with Praestol 650 (Pr650) (0.75mg/L).

The uniform nature of the dependence of the settled water's turbidity after coagulation on the dose of coagulants, which passes through a maximum (Figure 6) when using iron and aluminum coagulants, indicates the same mechanism of coagulation of waters with high color.

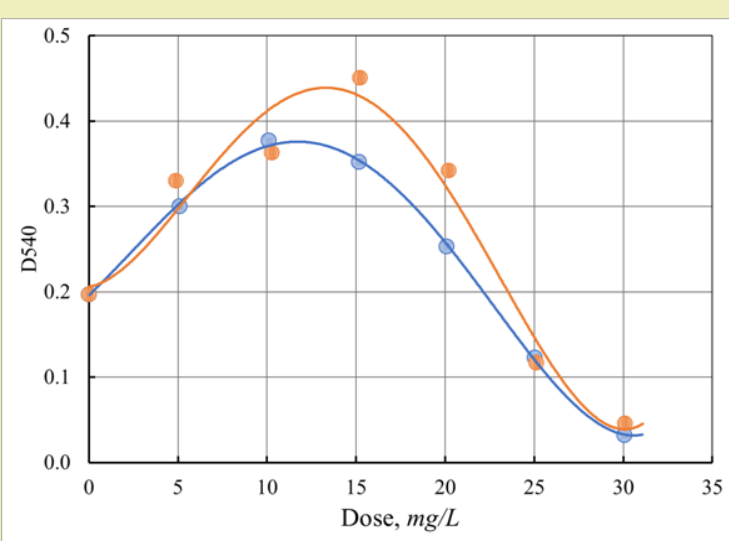

Figure 6: Dependence of turbidity (D 540) of coagulated and settled water of the Orsha river with the use of ASFC and AS.

The leading role belongs to the coagulant's chemical interactions with humic and fulvic acids, which determine the color of the purified water, which leads to the formation of insoluble and soluble polymer complexes. As a result, with an increase in the coagulant dose, the optical density of the purified water first increases to a maximum, at which the complete binding of humic and fulvic acids into polymer complexes occurs, after which the rate of their coagulation and precipitation process becomes predominant, and the optical density of water begins to decrease. It should also be noted that for the composite coagulants ASFC and ISFC, the maximum value of optical density and the rate of its decrease is higher than for single-component base coagulants, which is obviously due to the higher numerical concentration and larger particle sizes formed as a result of the interaction of the hydrolysis products of the coagulant and humate-sulfate polymer complexes.

The activated coagulant ASFC is more effective than the non-activated coagulant ASFC in reducing the purified water's turbidity and color at doses less than optimal (Figures 5 and 6). Activated ISFC further increases the initial water's color compared with the non-activated coagulant ISFC (Figures 7 and 8), which can be used 
to isolate dissolved impurities from the water form insoluble complexes with the coagulant. Under the same conditions, activated ASFC provides lower turbidity and color of purified water compared to non-activated coagulant (Figures 9 and 10). It can be assumed that activation in magnetic fields affects iron hydroxo complexes' structural change since they have ferromagnetic properties.

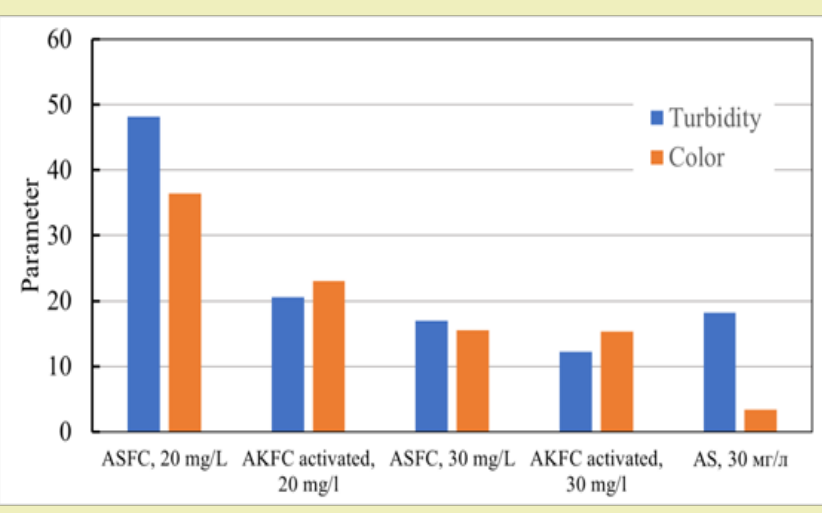

Figure 7: Coagulation of the Orsha river at a temperature of $10^{\circ}$ (initial turbidity $=25 \mathrm{mg} / \mathrm{L}$, color $260^{\circ}$, dose $20-30 \mathrm{mg} / \mathrm{L}$ ).

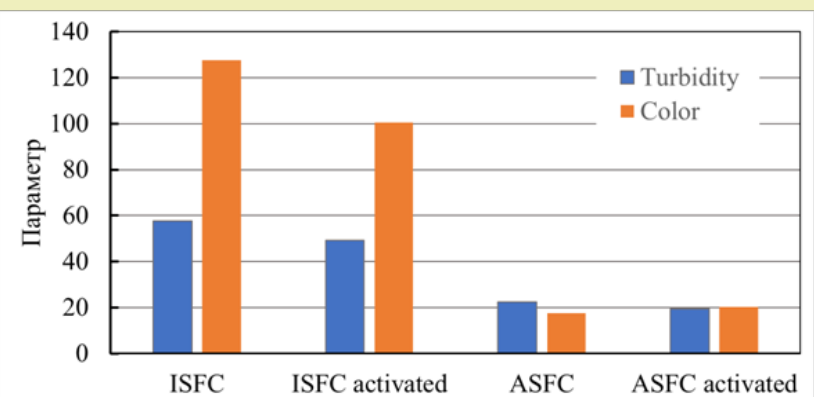

Figure 8: Coagulation of the Volga water at a temperature of $10^{\circ}$ (initial turbidity $10 \mathrm{mg} / \mathrm{L}$, color $85^{\circ}$, dose $15 \mathrm{mg} / \mathrm{L}$ ).

Thus, for the purification of colored waters with low turbidity, the coagulant ASFC can be used before and after its activation in a magnetic field. The effectiveness of the use of ASFC is much higher, and the doses are $20-30 \%$ lower than that of aluminum sulfate when used together with the cationic flocculant Praestol 650,

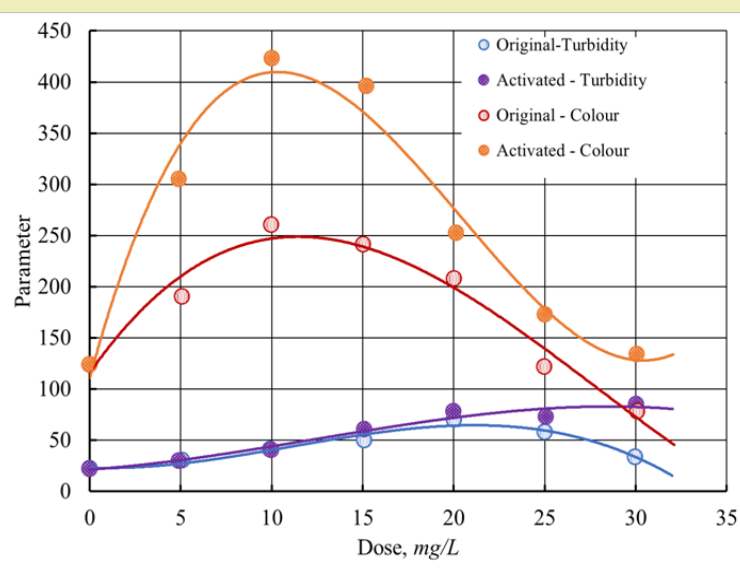

Figure 9: Dependence of turbidity and color of groundwater on the dose of ISFC activated and non-activated.

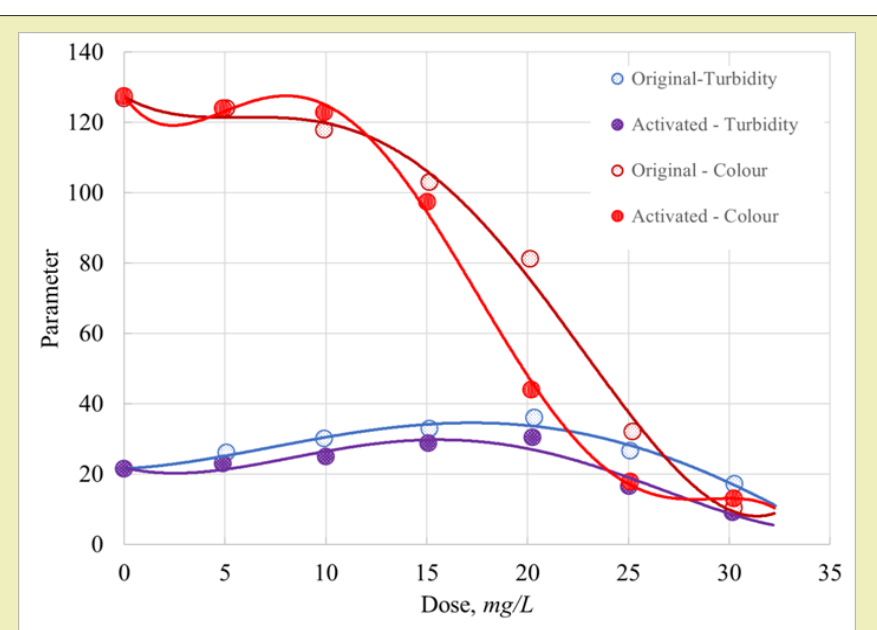

Figure 10: Dependence of the turbidity of the settled groundwater and the color of filtered groundwater on the dose of ASFC before and after activation.

as well as when purifying colored waters with a high color value of $260-300^{\circ}$ and with low turbidity. The characteristics of settled river water after coagulation treatment using the optimal doses of coagulants ASFC and AS are presented in Table 1.

Table 1: The effectiveness of the use of the coagulant ASFC and AS together with Praestol 650 for the purification of natural waters by settling.

\begin{tabular}{|c|c|c|c|c|c|c|c|}
\hline River & Coagulant* & Dose, mg/L & $\begin{array}{c}\text { Turbidity**, } \\
\text { mg/L }\end{array}$ & $\begin{array}{c}\text { Chromaticity } \\
*^{*} \text {, degrees }\end{array}$ & $\mathrm{pH}^{* *}$ & $\begin{array}{l}\text { Turbidity reduc- } \\
\text { tion effect, } \%\end{array}$ & $\begin{array}{l}\text { The effect of color } \\
\text { reduction, } \%\end{array}$ \\
\hline \multirow{2}{*}{ Tvertsa } & AS & 15 & $4,7 / 12$ & $17 / 102$ & $6,2 / 7,78$ & 61 & 83,3 \\
\hline & ASFC & 15 & $4,7 / 12$ & $17 / 102$ & $6,6 / 7,78$ & 61 & 83,3 \\
\hline \multirow{2}{*}{ Volga } & AS & 15 & $2 / 10$ & $10,6 / 85$ & $6,7 / 7,75$ & 80 & 87,5 \\
\hline & ASFC & 15 & $1,3 / 10$ & $12,7 / 85$ & $6,5 / 7,75$ & 87 & 85,1 \\
\hline \multirow{2}{*}{ Orsha } & AS & 20 & $8 / 25,6$ & $36 / 288$ & $5,9 / 7,48$ & 68,7 & 87,5 \\
\hline & ASFC & 25 & $7,3 / 25,6$ & $25,5 / 288$ & $6,3 / 7,48$ & 71,5 & 91,1 \\
\hline
\end{tabular}

*- Coagulant $/$ flocculant dose ratio $=20$.

${ }^{* *}$-in the numerator is the indicator of water quality after cleaning, in the denominator - before cleaning. 
The effectiveness of the use of coagulants ASFC and ISFC for the treatment of oily wastewater

The results obtained on the efficiency of reducing the content of suspended solids (turbidity) and oil products in various types of wastewater10 allow us to draw the following conclusions.
The optimal doses of coagulants ASFC, ISFC, and basic coagulants are the same when treating wastewater of the same composition. Doses of iron-containing coagulants are equal to or less than the optimal doses of aluminum-containing coagulants (Table 2). Coagulant ISFC can be used only for the purification of natural waters with low color.

Table 2: The effectiveness of the use of the coagulant ASFC and AS together with Praestol 650 for the purification of natural waters by settling.

\begin{tabular}{|c|c|c|c|c|c|c|c|}
\hline $\begin{array}{l}\text { Wastewa- } \\
\text { ter }\end{array}$ & Coagulant * & Dose, $\mathrm{mg} / \mathrm{L}$ & $\begin{array}{c}\text { Turbidity **, } \\
\text { mg/L }\end{array}$ & $\begin{array}{l}\text { Petroleum } \\
\text { products **, } \\
\text { mg/L }\end{array}$ & $\mathrm{pH}^{* *}$ & $\begin{array}{l}\text { Turbidity reduc- } \\
\text { tion effect, } \%\end{array}$ & $\begin{array}{c}\text { The effect of reducing } \\
\text { the content of oil prod- } \\
\text { ucts, } \%\end{array}$ \\
\hline \multirow{5}{*}{$\begin{array}{l}\text { Oil refin- } \\
\text { ery }\end{array}$} & AS & 20 & $6 / 47$ & $2,3 / 5,5$ & $6,9 / 7,48$ & 87,2 & 58 \\
\hline & ASFC & 20 & $9 / 47$ & $2,5 / 5,5$ & $6,9 / 7,48$ & 80,9 & 54,5 \\
\hline & IS & 10 & $8,7 / 47$ & $4,3 / 5,5$ & $8,5 / 7,48$ & 81,5 & 22 \\
\hline & ISFC & 10 & $8,7 / 47$ & $2,8 / 5,5$ & $8,5 / 7,48$ & 81,5 & 49 \\
\hline & -- & 20 & $8 / 47$ & $2,1 / 5,5$ & $8,5 / 7,48$ & 83 & 61,8 \\
\hline \multirow{4}{*}{ Car wash } & AS & 5 & $61 / 107$ & $10,6 / 140$ & $6,5 / 7,1$ & 43 & 92,4 \\
\hline & ASFC & 5 & $43 / 107$ & $10,6 / 140$ & $6,5 / 7,1$ & 60 & 92,4 \\
\hline & IS & 5 & $38 / 75$ & $2,4 / 50,5$ & $9,9 / 7,1$ & 49 & 95,2 \\
\hline & ISFC & 5 & $28 / 75$ & $0,98 / 50,5$ & $10,2 / 7,1$ & 63 & 98,1 \\
\hline \multirow{4}{*}{$\begin{array}{l}\text { Industrial } \\
\text { storm } \\
\text { sewer }\end{array}$} & AS & 10 & $26 / 154$ & $7,4 / 83$ & $5,9 / 7,6$ & 83 & 87,5 \\
\hline & ASFC & 10 & $26 / 154$ & 7,3/83 & $6,3 / 7,6$ & 83 & 91,1 \\
\hline & IS & 5 & $36 / 84$ & $3,95 / 47$ & $10,3 / 7,6$ & 57 & 91,6 \\
\hline & ISFC & 5 & $22 / 84$ & $2,25 / 47$ & $10,1 / 7,6$ & 74 & 95,2 \\
\hline
\end{tabular}

*- Dose ratio coagulant / flocculant 10.

**- in the numerator is the indicator of water quality after cleaning, in the denominator - before cleaning

The coagulant ASFC and AS have approximately the same efficiency for reducing oil products' content in the studied wastewater. In combination with the cationic flocculant Praestol 650, the coagulant ASFC reduces turbidity better than aluminum sulfate (Figure 11).

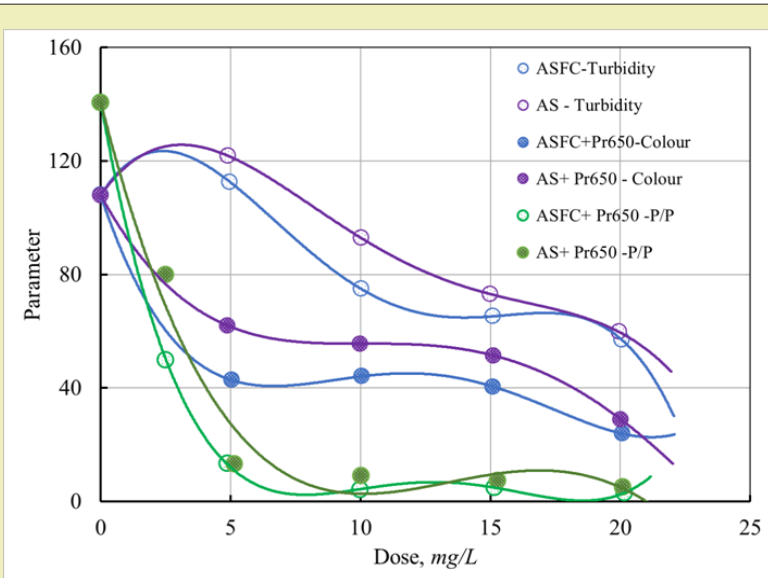

Figure 11: Dependence of the quality of the car wash wastewater settled after coagulation on the dose of aluminum-containing coagulants without flocculant and with flocculant Praestol 650 (Pr650) at their ratio of 10:1 and $\mathrm{pH}=6.4-7.0$. P/P - Petroleum products.

When using ISFC, the content of oil products in purified water is significantly lower than when using ferrous sulfate (Figure 12, Table 2).

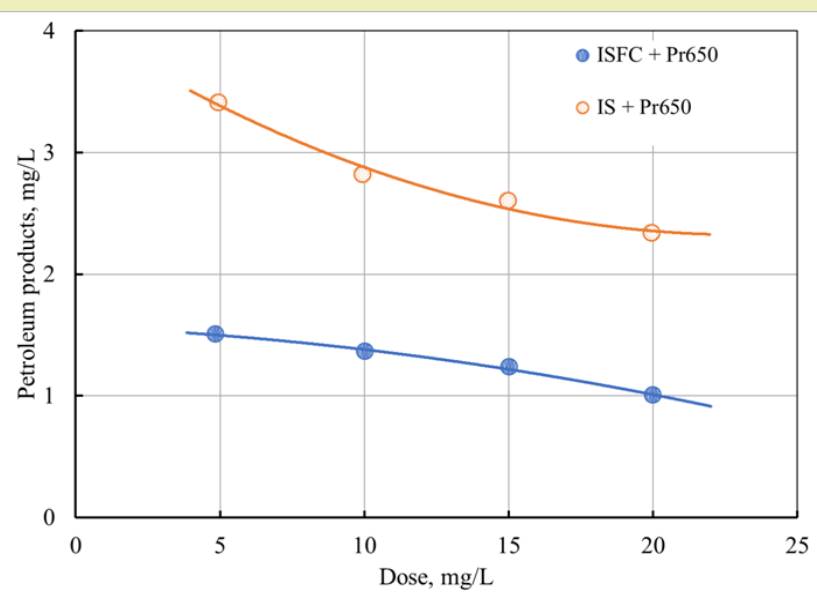

Figure 12: Dependence of the oil products' content in the settled wastewater of a car wash on the dose of coagulants when used together with the flocculant Praestol 650 (Pr650) at a ratio of $10: 1$ and $\mathrm{pH}=9.8-10.4$. The content of oil products in the source water $=50.5 \mathrm{mg} / \mathrm{L}$.

Recommendations for the Use of Coagulants ASFC and ISFC for the Purification of Natural River Waters and Industrial Wastewaters

\section{General provisions}

Coagulants ASFC and ISFC (TU 2163-001-3578061-08) are produced at "Trivektr" company based on aluminum sulfate and iron sulfate, respectively, in the presence of silicic acid salts. They are 
powdery products that are readily soluble in water. Coagulant solutions have an acidic environment and are stable during storage.

Coagulants ASFC and ISFC, as well as other aluminum- and iron-containing coagulants, are intended for the enlargement of fine suspended contaminants and the release of soluble contaminants that can enter into chemical interactions with coagulants with the formation of insoluble substances with the aim of their subsequent separation by settling, filtration or flotation. ${ }^{1}$

\section{Scope of coagulants}

- Coagulants ASFC and ISFC are recommended to be used in technological schemes of natural and wastewater purification by settling, flotation, and filtration. To mix reagents with water and form flakes of the required size, the purification schemes, as well as using traditional coagulants, must include mixers and flocculation chambers. ${ }^{2}$

- Coagulant ASFC can be used instead of aluminum sulfate to intensify natural and wastewater treatment at existing treatment facilities.

- $\quad$ Coagulant ISFC can be used at existing treatment facilities instead of ferrous sulfate to intensify natural waters and wastewater purification, including oily wastewater. Coagulant ISFC and ferrous sulfate are not recommended for the purification of colored waters containing humic acids.

- When clarifying water by settling, coagulants ASFC and ISFC are recommended to be used in conjunction with cationic flocculants such as Praestol 650 at a dose ratio of reagents 20:1 for natural waters and 10:1 for wastewater.

\section{Preparation and dosing of ASFC and ISFC coagulants solutions}

- $\quad$ Coagulants ASFC and ISFC are recommended to be dosed into purified water, depending on the consumption, in the form of 1-5\% solutions of aluminum or iron oxides.
- The formula calculates the required amount of a commercial product $\mathrm{G}(\mathrm{kg})$ required to prepare $1000 \mathrm{~kg}$ of a coagulant solution of the required percentage concentration:

$$
\mathrm{G}=1000 \mathrm{C}_{\mathrm{Dos}} / \mathrm{C}_{\mathrm{Com}}
$$

Where $C_{D o s}$ и $C_{C o m}$-Percentage concentrations of the dosed working solution and the commercial product in terms of metal oxide.

- $\quad$ The flow rate of the working solution of the coagulant $\left(Q_{w}\right)$ to ensure the required dose of the coagulant $D_{\text {coag }}$ for water purification is determined by the formula:

$$
\begin{aligned}
& Q_{w}\left[\mathrm{~kg} \cdot \mathrm{h}^{-1}\right]=\left(\mathrm{Q}_{\mathrm{aq}}\left[\mathrm{m}^{3} \cdot \mathrm{h}^{-1}\right] \cdot \mathrm{D}_{\text {coag }}\left[\mathrm{mg} \cdot \mathrm{l}^{-1}\right]\right) /\left(10 \cdot \mathrm{C}_{\text {Dos }}[\%]\right) \\
& \mathrm{Q}_{\mathrm{w}}\left[1 \cdot \mathrm{h}^{-1}\right]=\left(\mathrm{Q}_{\mathrm{w}}\left[\mathrm{kg} \cdot \mathrm{h}^{-1}\right]\right) / \rho
\end{aligned}
$$

- Where $\rho$ - the density of the dosed coagulant solution.

- The preparation of ASFC and ISFC solutions can be carried out using the same technological equipment as coagulants of aluminum and iron (II) sulfates. ${ }^{3}$

- Due to insoluble impurities in the coagulants, the dosage of the prepared solutions of ASFC and ISFC can be carried out using the same metering pumps as coagulants - aluminum and ferrous iron sulfate, but after preliminary settling of the prepared solutions.

\section{The effectiveness of the use of coagulants ASFC and ISFC}

The effectiveness of the use of coagulants ASFC and ISFC for the purification of natural and wastewaters of the same composition is comparable to the effectiveness of aluminum sulfate and ferrous sulfate, respectively, at equal or lower doses of ASFC and ISFC (for aluminum or iron oxide). Doses of reagents and the effectiveness of coagulation purification of natural waters and oily wastewater according to the scheme: mixing, flocculation, settling, using coagulants ASFC and ISFC and the corresponding base coagulants, alumi-

\begin{tabular}{|c|c|c|c|c|c|c|c|}
\hline River & Coagulant * & $\begin{array}{c}\text { Dose by } \\
\mathrm{Al}_{2} \mathrm{O}_{3}, \mathrm{mg} / \mathrm{L}\end{array}$ & $\begin{array}{c}\text { Turbidity **, } \\
\text { mg/L }\end{array}$ & $\begin{array}{l}\text { Chromaticity } \\
* * \text {, degree }\end{array}$ & $\mathrm{pH}^{* *}$ & $\begin{array}{l}\text { Turbidity reduc- } \\
\text { tion effect, } \%\end{array}$ & $\begin{array}{c}\text { Color reduction effect, } \\
\%\end{array}$ \\
\hline \multirow{2}{*}{ Tvertsa } & AS & 15 & $4,7 / 12$ & $17 / 102$ & $6,2 / 7,78$ & 61 & 83,3 \\
\hline & ASFC & 15 & $4,7 / 12$ & $17 / 102$ & $6,6 / 7,78$ & 61 & 83,3 \\
\hline \multirow{2}{*}{ Volga } & AS & 15 & $2 / 10$ & $10,6 / 85$ & $6,7 / 7,75$ & 80 & 87,5 \\
\hline & ASFC & 15 & $1,3 / 10$ & $12,7 / 85$ & $6,5 / 7,75$ & 87 & 85,1 \\
\hline \multirow{2}{*}{ Orsha } & AS & 20 & $8 / 25,6$ & $36 / 288$ & $5,9 / 7,48$ & 68,7 & 87,5 \\
\hline & ASFC & 25 & $7,3 / 25,6$ & $25,5 / 288$ & $6,3 / 7,48$ & 71,5 & 91,1 \\
\hline
\end{tabular}
num sulfate and ferrous sulfate, are presented in Tables 3.1 and 3.2.

Table 3.1: The effectiveness of the use of the coagulant ASFC and AS together with Praestol 650 for the purification of natural waters by settling.

*- Dose ratio coagulant / flocculant 20.

${ }^{* *}$ - in the numerator is the indicator of water quality after cleaning, in the denominator - before cleaning

Table 3.2: The effectiveness of the use of coagulants ASFC and ISFC together with Praestol 650 for the purification of oily wastewater by settling (with adjustment of the $\mathrm{pH}$ value of the treated water).

\begin{tabular}{|c|c|c|c|c|c|c|c|}
\hline $\begin{array}{c}\text { Wastewa- } \\
\text { ter }\end{array}$ & Coagulant * & $\begin{array}{c}\text { Dose for metal } \\
\text { oxide, } \mathbf{m g} / \mathbf{L}\end{array}$ & $\begin{array}{c}\text { Turbidity **, } \\
\mathbf{m g / L}\end{array}$ & $\begin{array}{c}\text { Petroleum prod- } \\
\text { ucts } * * \mathbf{m g} / \mathbf{L}\end{array}$ & $\mathbf{p H}^{* *}$ & $\begin{array}{c}\text { Turbidity reduc- } \\
\text { tion effect, } \%\end{array}$ & $\begin{array}{c}\text { The effect of reducing the } \\
\text { content of oil products, \% }\end{array}$ \\
\hline \multirow{2}{*}{$\begin{array}{c}\text { Oil refin- } \\
\text { ery }\end{array}$} & AS & 20 & $6 / 47$ & $2,3 / 5,5$ & $6,9 / 7,48$ & 87,2 & 58 \\
\cline { 2 - 8 } & ASFC & 20 & $9 / 47$ & $2,5 / 5,5$ & $6,9 / 7,48$ & 80,9 & 54,5 \\
\hline
\end{tabular}




\begin{tabular}{|c|c|c|c|c|c|c|c|}
\hline & IS & 10 & $8,7 / 47$ & $4,3 / 5,5$ & $8,5 / 7,48$ & 81,5 & 22 \\
\hline & ISFC & 10 & $8,7 / 47$ & $2,8 / 5,5$ & $8,5 / 7,48$ & 81,5 & 49 \\
\hline & -- & 20 & $8 / 47$ & $2,1 / 5,5$ & $8,5 / 7,48$ & 83 & 61,8 \\
\hline \multirow{4}{*}{ Car wash } & AS & 5 & $61 / 107$ & $10,6 / 140$ & $6,5 / 7,1$ & 43 & 92,4 \\
\hline & ASFC & 5 & $43 / 107$ & $10,6 / 140$ & $6,5 / 7,1$ & 60 & 92,4 \\
\hline & IS & 5 & $38 / 75$ & $2,4 / 50,5$ & $9,9 / 7,1$ & 49 & 95,2 \\
\hline & ISFC & 5 & $28 / 75$ & $0,98 / 50,5$ & $10,2 / 7,1$ & 63 & 98,1 \\
\hline \multirow{4}{*}{$\begin{array}{l}\text { Industrial } \\
\text { storm } \\
\text { sewer }\end{array}$} & AS & 10 & $26 / 154$ & $7,4 / 83$ & $5,9 / 7,6$ & 83 & 87,5 \\
\hline & ASFC & 10 & $26 / 154$ & $7,3 / 83$ & $6,3 / 7,6$ & 83 & 91,0 \\
\hline & IS & 5 & $36 / 84$ & $3,95 / 47$ & $10,3 / 7,6$ & 57 & 91,6 \\
\hline & ISFC & 5 & $22 / 84$ & $2,25 / 47$ & $10,1 / 7,6$ & 74 & 95,2 \\
\hline
\end{tabular}

*- Dose ratio coagulant / flocculant 10.

**- in the numerator is the indicator of water quality after cleaning, in the denominator - before cleaning

Optimal doses and $\mathrm{pH}$ values (in the range from 6.5 to 7.5 ) for water purification with coagulant ASFC are in the same range of values as when using aluminum sulfate. They should be specified in each specific case using trial coagulation (see section 2.2). Optimal doses and $\mathrm{pH}$ values (within 9-9.5) for water purification with ISFC coagulant are in the same range of values as when using ferrous sulfate. They should be specified in each specific case by a trial coagulation method (see section 2.2). The $\mathrm{pH}$ can be adjusted with alkaline reagents (caustic soda, milk of lime, etc.).

\section{Conclusion}

The coagulating properties of the coagulants ASFC and ISFC have been studied, and recommendations have been developed for their use for the purification of natural and wastewaters. It has been experimentally shown that the composite flocculant ASFC, at equal or lower doses, is more effective than aluminum sulfate when treating waters with high color, medium color, and low turbidity in terms of the color index. The simultaneous achievement of a high-water purification rate by settling in terms of color and turbidity is achieved when using ASFC together with the flocculant Praestol 650 at a coagulant: flocculant ratio of 20. Composite coagulant ISFC and ferrous sulfate do not provide the required effect of purification of natural waters in terms of color, even in an alkaline medium, which makes their use for these purposes impractical. It has been experimentally shown that the composite flocculant ISFC is the most effective coagulant among the tested coagulants (AS, IS, ASFC, ISFC) to purify oily wastewater when it is used together with the Praestol 650 flocculant. Composite coagulant ASFC and aluminum sulfate have the same efficiency in the treatment of oily wastewater.

\section{Acknowledgments}

None.

\section{Funding}

None.

\section{Conflicts of Interest}

Author declares that there is no conflict of interest.

\section{References}

1. Kulsky LA, Strokach PP. Natural water purification technology. Kyiv: Higher school. 1986. p. 352.

2. Getmantsev SV, Nechaev IA, Gandurina LV. Industrial wastewater treatment with coagulants and flocculants. Moscow: ASV Publishing House. 2008. p. 272.

3. Water supply. External networks and facilities. SNiP 2.04.02.84.-M: Stroyizdat. 1985. p. 131.

4. Zapolsky AK, Baran AA. Coagulants, and flocculants in water purification processes: Properties. L: Chemistry. 1987. p. 208.

5. Linevich SN, Getmantsev SV. Coagulation method of water treatment: theoretical foundations and practical use. South Russian State Technical University; OJSC "AURAT". Moscow: Nauka. 2007. p. 230.

6. Kudryavtsev PG, Nedugov AN, Ryabov VA, et al. The method for producing an aluminum-silicon flocculant-coagulant and method of water purification using it. Patent RF № 2388693, by application № 2008131241. 2008.

7. Nedugov AN, Volkova MA, Kaysin AV, et al. The method for producing a composite aluminum-silicon-coagulant flocculant. Patent RF № 2447021, by application № 2010133345/05. 2010.

8. Nedugov AN, Volkova MA, Kaysin AV, et al. The method for producing iron-silicon flocculant coagulant and method of water treatment. Patent RF № 2438993, by application № 2010133344/05. 2010.

9. Kudryavtsev PG, Kudryavtsev NP. New high-tech composite flocculantscoagulants as an alternative to the known reagents for water treatment. International Scientific Journal "Alternative Ener gy and Ecology". 2016;93-103.

10. Kudryavtsev PG, Kudryavtsev NP. New Composite Flocculants Coagulants as an Alternative to the Known Water Treatment Agents. Journal “Scientific Israel-Technological Advantages". 2016;18(3):84-97.

11. Kudryavtsev PG, Kudryavtsev NP, Figovsky OL. Matrix-isolated nanocomposite flocculants, coagulants for purification of natural and wastewaters from oil pollution, Proceedings of the $\mathrm{V}$ International Scientific and Practical Conference "NANOTECHOILGAS-2016"; Moscow. Moscow, Oil \& Gas. 2016;91-96.

12. Kudryavtsev PG, Kudryavtsev NP, Figovsky OL. Purification of industrial and wastewater using matrix-isolated nanocomposite flocculantcoagulants. Nanotechnologies in Construction. 2017;9(3):44-61.

13. Kudryavtsev P, Figovskiy O. Matrix-Isolated Nanocomposites Alumina-Silicon Flocculants-Coagulants. Journal of Physical Science and Application. 2017;7(3):25-36.

14. Kudryavtsev P, Figovsky O, Kudryavtsev N. Cleaning of natural and sewage water using new composite flocculants-coagulants. Engineers Don Gazette. 2017;4:1-18.

15. Kudryavtsev PG, Kudryavtsev NP. Wastewater treatment using matrixisolated nanocomposite flocculant-coagulants. Electronic scientific journal “Engineering Don Gazette”. 2018;3:1-32.

16. Kudryavtsev P, Kudryavtsev N. New Composite Flocculants-Coagulants Using for the Purification of Natural Surface Water. Journal "Scientific Israel-Technological Advantages". 2020;22(2):46-78. 
17. Kudryavtsev P, Kudryavtsev N. Treatment of Natural Surface Waters Using New Composite Flocculants-Coagulants. International Journal of Hydrology (IJH). 2020;4(5): 211-227.

18. Klassen VI. Magnetic treatment of pulp before pyrite flotation. Nonferrous metals. 1969.

19. Klassen VI, Orel MA, Tsapkov NT, e al. On improving the flotation of nonsulfide minerals by magnetic treatment of aqueous solutions of reagents. Proceedings of universities. Non-ferrous metallurgy. 1968.
20. Klassen VI. Magnetization of water systems. $-2^{\text {nd }}$ ed., Moscow: Chemistry. 1982. p. 296.

21. Shakhov AI, Shiryaev AV, Dushkin SS. Proceedings of universities. Construction and architecture. 1963;11-12:214-217.

22. Shakhov AI, Dushkin SS. Proceedings of universities. Building and architecture. 1963;(11-12):214-215. 